\begin{tabular}{|c|c|c|}
\hline$\overline{7}$ & $\begin{array}{c}\text { International Journal of Current Research } \\
\text { and Academic Review }\end{array}$ & 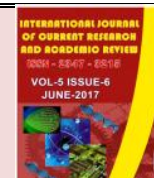 \\
\hline $\begin{array}{l}\text { EXCELLENT } \\
\text { PUBLISHERS }\end{array}$ & $\begin{array}{c}\text { ISSN: 2347-3215 (Online):,,;Volume 5:,;NiNumber } 6 \text { (June-2017) } \\
\text { Journal homepage: http://www.ijcrar.com }\end{array}$ & \\
\hline
\end{tabular}

doi: https://doi.org/10.20546/ijcrar.2017.506.005

\title{
Gymnosperm: A Review
}

\author{
Teena Agarwal* and Priyanka Danai
}

Banasthali University, Niwai, India

*Corresponding author

\begin{abstract}
Gymnosperms are the plants of evolutionary importance from Mesozoic era to till now we can see the all evolutionary aspects of this remarkable group of plants. In India uttarakhand, Kashmir and the valleys of the Nilgiris are the point of distribution of the gymnosperms. However due to rapid change in the anthropogenic activities this remarkable group of the plants is now at the line of extinction, now a very few plants are exist which are the representative of the group. Planned cultivation and conservation of the group is required for the maintenance of the plants in that planet.
\end{abstract}

\section{Article Info}

Accepted: 05 June 2017

Available Online: 20 June 2017

Keywords

Gymnosperms, Remarkable group,

Extinction, Distribution.

\section{Introduction}

The Gymnosperms are a group of seed-producing plants that includes conifers, cycads, Ginkgo, and Gnetales (Coulter and Chamberlain, 1910). The term "Gymnosperm" comes from the Greek composite word

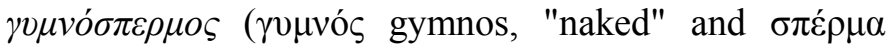
sperm, "seed"), meaning "Naked seeds", after the unenclosed condition of their seeds (called ovules in their unfertilized state) (Engler and Prantl, 1926). Their naked condition stands in contrast to the seeds and ovules of flowering plants (angiosperms), which are enclosed within an ovary.

Gymnosperm seeds develop either on the surface of scales or leave, often modified to form cones, or at the end of short stalks as in Ginkgo (Engler, 1986). The gymnosperms and angiosperms together compose the spermatophytes or seed plants. By far the largest group of living gymnosperms are the conifers (pines, cypresses, and relatives), followed by cycads, Gnetophytes (Gnetum, Ephedra and Welwitschia), and Ginkgo (a single living species) (Sporne, 1965; McLoughlin and Vivi Vajda, 2005).

\section{Definition of gymnosperms}

Gymnosperms are the plants have the remarkable history, since they are the best product of the evolution. They have many features of the combination of the characters. The morphology of the plants shows all the features of the evolutionary significance (Harris, 1964). The anatomy of the plants of stems and the roots has the combination of the many features which shows the evolution from the aquatic to the land adaptations. However the adaptation pattern of the gymnosperms' are low from the angiosperms' since they are the much evolved plants in the evolution of the plant groups (Eames, 1961).

Gymnosperms were flourished in the Mesozoic era, this was the era of the reptiles and the other giganteious organism. Well at that era cycads were abundant in the distribution in all over the globe, in this series many extinct plants exist which have a tremendous evolutionary significance, now palaeobotanical evidences of these plants can be seen in all over the world like in India Rajmahal hills are the point of distribution of many gymnosperms'. A very significant 
aspect of the plants (progressive evolution) can be seen in that era (Harris, 1964). Seed habit was once observed in the pteridophytes but complete seeds can be seen in the gymosperms, first time in the evolution seeds appeared in gymnosperms, from cycadles to the gnetales seeds have been seen from giganteious cycadales to the miniatures gnetales (Stevenson, 1990).

However the fruit habit has been observed only in some extinct gymnosperms like the calamitales and the some extinct ferns but the complete seed with fruit has been observed only in the fossil angiosperms and the living angiosperms.

One crucial step in the evolutionary history of all plants was the development of seeds. Seeds provide a viable means for dispersal of offspring without the need for water. They are more efficient of dispersal and allow plants to exist away from direct sources of water (Van Tieghem, 1898).

Gymnosperms were the first plants to have seeds. They are often referred to as having naked seeds because they do not have flowers, and their seeds develop on the surface of the reproductive structures of the plants that has been considered as the cones having the sporangia of the many kind the distributional pattern rather than being contained in a specialized ovary. These seeds are often found on the surfaces of cones and short stalks.

Gymnosperm is any vascular plant that reproduces by means of an exposed seed, or ovule-unlike angiosperms, or flowering plants, whose seeds are enclosed by mature ovaries, or fruits. The seeds of many gymnosperms (literally "naked seeds") are borne in cones and are not visible until maturity.

Taxonomists recognize four distinct divisions of extant (no extinct) Gymnospermous plants-Cycadophyta, Coniferophyta Ginkgophyta and Gnetophyta-with 88 genera and more than 1,000 species distributed throughout the world.

\section{Characteristics of gymnosperms (Fig. 1)}

Gymnosperms are a group of plants with the following some unique characteristics:

$>$ They do not have an outer covering or shell around their seeds (naked seed plants)

$>$ They do not produce flowers (the sporangia are distributed on the cones)
They do not produce fruits (these are the features of the angiosperms)

$>$ They are pollinated by the wind (much higher step in the evolution, in comparison to the other kinds of the pollination pattern)

$>$ Most plants are perennial and woody.( however fossils gymnosperms were have many kind of the distribution pattern in water as well as in xeric conditions) (Christenhusz et al., 2011).

They are xerophytic, with sunken stomata and thick cuticle.( adaptations to the land conditions)

- The xylem is without vessels and phloem lacks companion cells (a prominent feature of the angiosperms).

$>$ Reproductive organs are usually in the form of cones or strobilus. The male cones are made up of microsporophyll's and female cones are made up of megasporophylls (huge cones are the diagnostic feature of the gymnosperms).

$>$ Microsporophyll's bear microsporangia (900-1000 microsporangia in sori in Cycas and two microsporangia in Pinus sps) (distribution pattern of the sporangia is the featured of the Taxonomic significance).

$>$ Large number of microspores (pollen grains) is produced in microsporangia after reduction division which later forms male gametophytes (this again the step of the progressive evolution).

> Male gametophytes of all gymnosperms produce pollen tubes (the evolutionary reduction of the polen tubes can be seen form cycadales to the gnetales).

$>$ In the nucellus of megasporangia (ovules) one of the cells forms megaspore mother cell which after reduction division forms a linear tetrad of megaspores of which only one is functional (megasprogenesis).

$>$ Functional megaspore forms female gametophyte (also called endosperm). Thus the endosperm is a prefertilization tissue in gymnosperm(s) (endosperm of the gymnosperm is the feature of the taxonomic significance and have many economic importance).

$>$ On the micropylar end of female gametophyte are differentiated two or more archegonia (evolutionary reduction of the archegonia can be seen from the cycadles to the gnetales).

$>$ All gymnosperms are wind pollinated.

$>$ Usually polyembryony is found in seed although ultimately only one embryo survives (it is the adaptations for the survival of the species in the extreme conditions).

Archegonia lack neck canal cells.

$>$ Embryo bears two as in Cycas or more (10-11 in Pinus) cotyledons 


\section{Conservation aspects of the gymnopserms}

Gymnosperms have a great evolutionary history. Palaebotanical aspects of the gymnosperms show a tremendous history of these groups of the plants which were very fascinating and have a long history. Pteridospermales shows the a large assemblage of the plants which have so many features' of the combination of the characters
However due to the geological changes and the other factors these remarkable group of plants now at the line of the relicts.

From the last century due to the over exploitation of the natural resources in India and the other part of the world, these group of the plants have very limited distribution. The gymnosperms can be indentified only be some genera among them Cycadeles have only 10 genera and the conifers have assemblages of the genera's which shows the gymnosperms (Bitner, 2007).

Fig.1 General feature of Gymnosperm

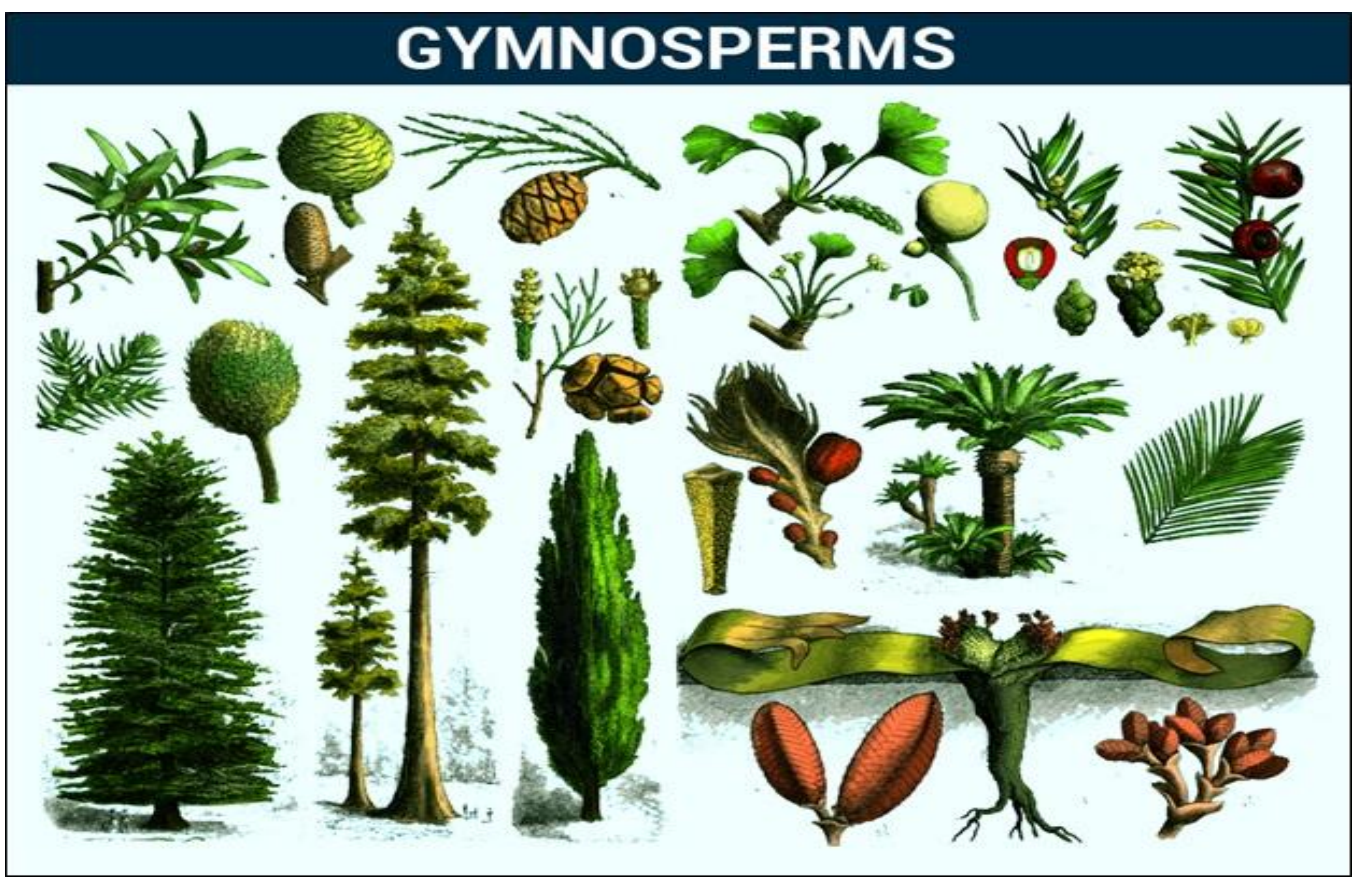

Some of the factors which are responsible for the degradation of that group can be elucidated as.

$>$ Overcutting of the forest for the different purposes.

$>$ Degradation of the forest ecosystem

$>$ Habitat destructions due to many anthropogenic factors.

$>$ Some of the diseases' are the main factors for the degradation of the many genera.

$>$ These plants have long evolutionary history but changes in the climate and the other evolutionary reasons these plants cannot be acclimatize with the environment.

$>$ Unplanned uses of the gymnosperms' by the tribal communities and other peoples is also the main reasons for the degradation of the gymnosperms'

\section{Conclusion}

In the long history of the evolution of the plants many natural geological events occurs which were the reasons for the disappearances of the plant kingdom from the earth. These feature we can seen in the evolutionary history from palaeozoic to the recent Cenozoic era but these kinds of the succession pattern were very fruitful for another kinds of the vegetations (natural reasons for the establishment of the plants).

But in the last century and the few decades the rapid industrialization and urbanization is the main factor for the degradation of the plants form the earth. The anthropogenic factors have very negative consequences on the succession biology of the plants. Now the 
establishment rate of the plants is very low in comparison to the other time era.

Well gymnosperms have a very important evolutionary, economic and the ecological significance. From economic point of view they have tremendous importance. All the plant parts are the reservoirs of the many kinds of the complex metabolites which have very important economic as well as ecological significance. Conifers have been used from centauries for many purposes. Similarly cycadales and the gnetales also have very important role in the economics utilization of the plants.

A sustainable uses of the plants is an essential features for the conservation of this remarkable group of the plants. Since in that era humans have many kinds of the diseases', so by planned uses of these plants one can trace out the solutions of all diseases' on the planet (changes habitat).

In addition a number of the environmental problems also exist, due to rapid industrialization, so they can be used for solution of the many environmental problems.

Overall human need is to be saved with these groups of the plants and helpful for saving of vegetation and other species on the planet.

\section{References}

Ansari, A. A., and Ghana Nand. 1985. Some medicinal plants of Pauri Garhwal. Himalayan Chem. Pharm. Bull. 2:42-44.

Armstrong, Wayne P. 2008. Cycad Distribution and Continental Drift. Available online at: http://waynesword.palomar.edu/cntdrift.htm.

Ash, Sidney R, and Geoffrey T Creber. 2003. The Late Triassic Araucarioxylon arizonicum Trees of the Petrified Forest National Park, Arizona, USA. Paleontology 43 (1): 15-28.

\section{How to cite this article:}

Teena Agarwal and Priyanka Danai. 2017. Gymnosperm: A Review. Int.J.Curr.Res.Aca.Rev. 5(6), 38-41. doi: https://doi.org/10.20546/ijcrar.2017.506.005
Bitner, Richard L. 2007. Conifers for Gardens: An Illustrated Encyclopedia. Portland, Oregon: Timber Press.

Christenhusz, M. J. M., J. L. Reveal, A. K. Farjon, M. F. Gardner, R. R. Mill \& M. W. Chase. 2011. A new classification and linear sequence of extant gymnosperms. Phytotaxa 19: 55-70.

Farjon, Aljos. 2008. A Natural History of Conifers. Portland, Oregon: Timber Press.

Issar, R. K. 1981. Traditionally important medicinal plants and folklore of Uttarakhand Himalaya for animal treatment. J. Sci. Res. PI. Med. 2:61-66.

Jain, S. K., and A. Saklani. Observations on ethnobotany of the Tons Valley region in Uttarkashi Dist. of Northwest Himalaya. Mountain Research and Development, Boulder, Colorado, U.S.A. (In press)

Joshi, D. N., B. C. L. Shah, and R. K. Suri. 1982. Some medicinal plants of Rudranath Bugyal (Dist. Chamoli) U.P. Bull. Med. Ethnobot. Res. 3:2742.

Juyal, S. P., and M Nautiyal, S. 1981. Some medicinal plants of Garhwal hills - a traditional use. J. Sci. Res. PI. Med. 2:12-18.

McLoughlin, Stephen, and Vivi Vajda. 2005. Ancient Wollemi Pines Resurgent. American Scientist 93: 540-547.

Negi, K. S., J. K. Tiwari, and R. D. Gaur. 1985. Economic importance of some common trees in Garhwal Himalaya; an ethnobotanical study. Indian J. Forest. 8:276-289.

Sundriyal, R.C., S.C. Negi, A.P. Joshi, and R. Dhasmana. 1985. Some importanttant medicinal trees of Kotdwara, Lansdowne and vicinity. Himalayan Chem. Pharm. Bull. 2:45

Uniyal, R. 1960. Medicinal plants of commercial and traditional importance in Bhillangana valley of Tehri-Garhwal. Nagarjun 10:26-36. 